\title{
Criminal Justice Alcohol and Drug Screening in Practice: Using the Substance Abuse Subtle Screening Inventory to Identify Substance Use Disorder in Offenders
}

\author{
Nelson J.Tiburcio, PhD*; Scarlett L. Baker,AA; Kristin S. Kimmell, LCSW, LCAC
}

The SASSI Institute, 20I Camelot Lane, Springville, IN 47462, USA

\section{"Corresponding author}

Nelson J.Tiburcio, PhD

Chief Executive Officer, The SASSI Institute, Springville, IN 47462, USA;Tel. 800-726-0526; Fax. 800-546-7995; E-mail: research@sassi.com

\section{Article Information}

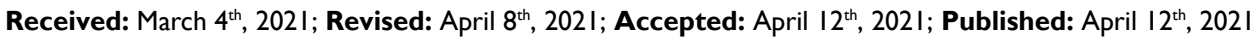

\section{Cite this article}

Tiburcio NJ, Baker SL, Kimmell KS. Criminal justice alcohol and drug screening in practice: Using the substance abuse subtle screening inventory to identify substance use disorder in offenders. Soc Behav Res Pract Open J. 202I; 6(I): I-6. doi: 10.17।40/SBRPOJ-6-129

\begin{abstract}
| ABSTRACT |
Objective

The substance abuse subtle screening inventory (SASSI) has been used successfully in correctional treatment settings and correctional screening since 1988. These screenings include outpatient evaluations of offenders within community settings, as well as assessments of incarcerated individuals within federal, state, city, and county correctional facilities. One key element towards reducing recidivism and reoffending, is that individuals receive treatment for substance use disorders (SUD's) while in the correctional system. While SUD is not the only contributing factor to criminality, it does significantly increase the likelihood of legal infraction and violations, placing these individuals at a higher risk of re-offending. Thus, identifying SUD as early as possible helps provide tailored treatment to those who need it, while simultaneously reducing the risk of future legal difficulties. Now in its fourth iteration (SASSI-4), this article discusses the SASSI screening tools' utility with criminal offenders and serving clinical needs, and reviews a case study of a young male's clinical evaluation while incarcerated.

Results

For this case study, we reviewed the SASSI-4 screening results of a 24-year-old male whom we will call "Bryon". Bryon was in his 4 th week of detention at a local mid-western jail in the United States. He was arrested after turning himself in for a prior domestic violence offense committed while under the influence of alcohol and for which he had fled the state. Bryon had one prior arrest (for receiving stolen property, which he subsequently traded for drugs). The intake counselor conducting Bryon's assessment had been meeting with him at the jail for several weeks. The court was particularly interested in determining the level of risk that Bryon would again flee the area.

\section{Conclusion}

This case presents us with a good example of the value of early identification of substance use disorder, and potential problems in criminal justice settings. Bryon's SASSI results clearly demonstrate a well-established pattern of substance misuse that will require relatively intensive intervention. Therefore, he may be a solid candidate for diversion into an alcohol and drug treatment program as a way of reducing the risk of future offenses.
\end{abstract}

Keywords

Subtle SUD screening; The SASSI Institute; Criminal offenders; Corrections; Recidivism; Alcohol and drug screening.

\section{INTRODUCTION}

$\mathrm{R}$ ecidivism among criminal offenders has always been a serious problem and remains so today. There are numerous factors that contribute towards this phenomenon, one of the most salient being substance use disorder (SUD). ${ }^{1,2}$ For intervention to be effective in reducing recidivism however, early identification and assignment to appropriate treatment is needed, particularly within institutional environments. ${ }^{3-6}$ A good example here, was a study conducted within the Stay ' $N$ Out therapeutic community at the Corcoran correctional facility in California dating back more than forty years. ${ }^{7}$ Although in its nascent stages at that time, this research on therapeutic communities within prison settings defined important advances in prison substance abuse treatment 
and reentry programs. Wexler's work and studies that followed, offered guiding observations and evidence-based practice describing prison substance abuse treatment that would ultimately facilitate the implementation of treatment for offenders with co-occurring mental illness and substance use disorders (COD). There have been multitudes of studies emanating from this seminal work and the literature in this regard is quite expansive..$^{8-10}$

One of the key findings that emerged from these various studies is the clear need to appropriately document these individuals' complex treatment needs, and examine if these necessities were indeed being met. Doing so often required various modifications to existing treatment paradigms, such that treatment became more tailored in order to facilitate its implementation, as well as document and measure individual and collective progress. ${ }^{4,5,10}$ As a result, clinicians required screening tools that helped reveal specific, often nuanced individual needs. Doing so facilitated inmate-referral to suitable programs, further ensuring a more appropriate, and individualized treatment regimen.

\section{ACCUARCY OF SELF-REPORT}

There is debate among researchers regarding the extent to which people are accurate and forthright in reporting their alcohol and drug use and its consequences. Most substance abuse screening inventories rely on people to acknowledge behaviors directly related to their substance use and are therefore composed of direct questions about substance use/misuse and its consequences, i.e., face valid questions. The substance abuse subtle screening inventory (SASSI) on the other hand, includes both subtle and face valid items because research findings indicated that using both types of scales significantly increased the accuracy of the instrument. ${ }^{2,11,12}$

Validation research on the SASSI-4 reported that criminal offenders acknowledged significantly less alcohol and illicit drug use and consequences on face valid scale (self-report) than those in substance use treatment programs, social service programs, and community settings. ${ }^{13}$ However, offenders showed no difference in their response to subtle questions when compared to those with substance use disorders in other settings. Within criminal justice settings, the SASSI-4 demonstrated overall screening accuracy of $95 \%$, despite attempts at minimization of substance use. Research findings also illustrate the strengths of using the SASSI-4 screening tool for criminal offenders when compared to entirely face-valid screens. ${ }^{14}$ That is, the inclusion of subtle items on the SASSI-4 as well as a scale to identify clients' level of defensive responding strengthens the ability of the SASSI-4 to accurately identify clients with substance use disorders compared to entirely face valid screens such (i.e., alcohol use disorders identification test (AUDIT), drug abuse screening tool (DAST), cut annoyed guilt eye-opener (CAGE])).

Offenders within correctional institutions will often present with co-occurring mental health problems. ${ }^{3,715}$ These issues, in tandem with legal offense history and substance use disorders, can ultimately affect their response patterns on the various assessments they are given. Our extant research on the SASSI-4 has shown its screening sensitivity is $98 \%$ in dual diagnosis clients; and specificity is $93 \%$ in persons diagnosed with non substance-related psychological disorders only (Table 1), producing an overall accuracy rate of $97 \%$ in people suffering from other psychological disorders. ${ }^{14}$

Another advantage of using the SASSI with correctional populations is that in addition to providing an overall decision rule about whether an individual has a high or low probability of having an SUD, it also includes a scale that identifies an individual's risk of incurring ongoing legal difficulties. The correctional (COR) scale, identifies individuals who are at a relative risk for legal problems or ongoing legal problems. By discussing an individual's elevated COR score with them, clinicians have an opportunity to help address their clients' negative behaviors, especially those potentially leading to ongoing legal difficulties. Individuals may benefit from exploration into behaviors and characteristics that put them at further risk. The SASSI-4 also offers an Rx scale, which is designed to assist in identifying likely prescription drug abuse. Additionally, since cultural factors in patterns of substance use and abuse is of significance, it is important to note that research on the SASSI-4 demonstrated no significant variations as a function of ethnic group membership throughout North America. ${ }^{14}$ The ethnic groups included 45 (3.7\%) American Indian or Alaska Native, 12 (1\%) Asian, Native Hawaiian or Pacific Islander, 133 (10.9\%) Black/African American, 86 (7.1\%) Hispanic American, 916 (75.4\%) White/Caucasian, 11 (0.9\%) Multiracial, and 12 (1\%) Other.

In addition to addressing denial, the SASSI tool enables clinicians to establish rapport with their client base, particularly when reviewing the results of each scale. The face valid scales on the SASSI-4 consist of the following: The face valid alcohol (FVA) and face valid other drug (FVOD) scales measure how often respondents have engaged in and experienced effects from the use of alcohol and other drugs within a specified time frame (e.g.,

\begin{tabular}{|c|c|c|c|}
\hline & \multicolumn{2}{|c|}{ SASSI-4 Screening Outcome } & \multirow[b]{2}{*}{ Total } \\
\hline & Test Positive & Test Negative & \\
\hline $\begin{array}{l}\text { Diagnosis } \\
\text { Criterion Positive for SUD and co-occurring disorder }\end{array}$ & 56-years & Female & 34-years \\
\hline Criterion Negative for SUD: non-SUD related disorder only & 5I-years & Female & 19-years \\
\hline Total & 317 & 63 & 380 \\
\hline \multicolumn{3}{|c|}{$\begin{array}{l}\text { Note. } 369 / 380 \text { cases correctly classified=97. } 1 \% \text { Overall Accuracy. Sensitivity=97.8\%; Specificity }=93.3 \% \text {; } \\
\text { Positive predictive value=98.7\%; Negative predictive value }=88.9 \% \text {. }\end{array}$} & \\
\hline
\end{tabular}




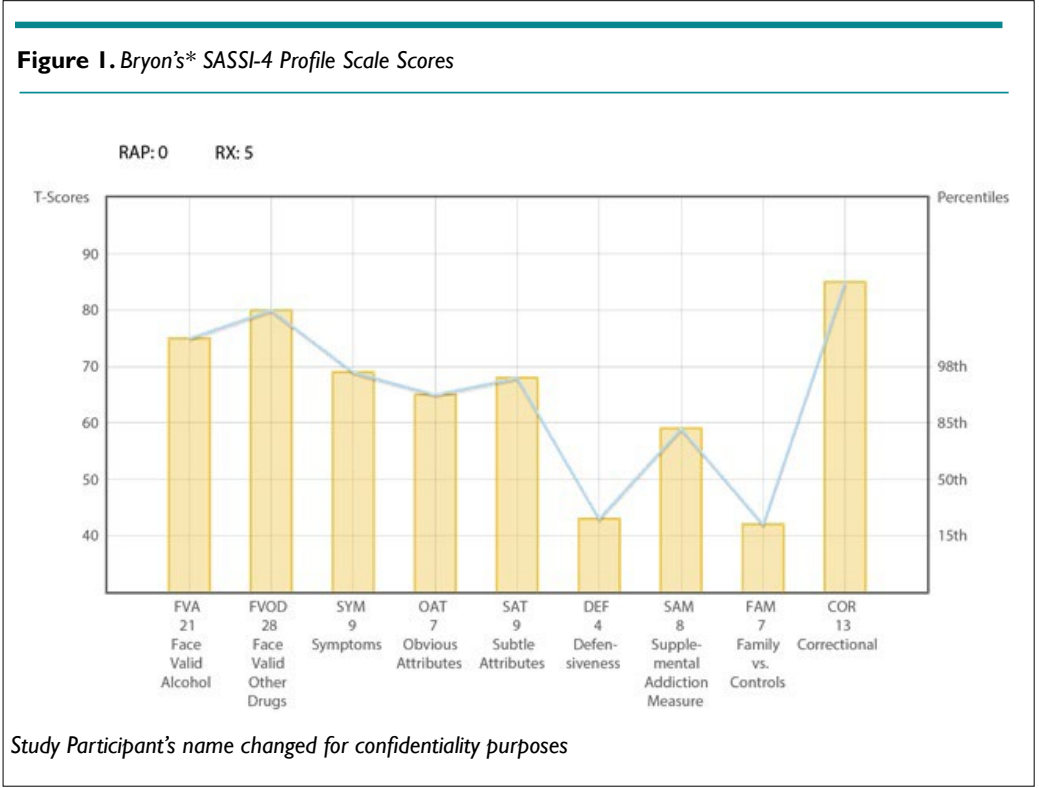

lifetime, past 12-months) (i.e., Gotten into trouble on the job, in school, or with law because of your drinking?; Misused medications or took drugs to forget school, work or family pressures?). The symptoms (SYM) scale measures the extent to which the client acknowledges the problems and consequences of their substance use history and contains face valid items (i.e., True or False: I have sometimes drunk too much.). The subtle scales consist of the following: The obvious attributes (OAT) scale is compiled empirically of items shown to discriminate between SUD criterion groups under standard instructions to answer honestly (i.e., True or False: I have not lived the way I should.). The subtle attributes (SAT) scale measures characteristics of individuals who have a substance use disorder that are less obvious than those measured by the OAT scale and consists of items found to discriminate between those with and without SUDs even when they attempted to hide signs of substance misuse (i.e., True or False: It is better not to talk about personal problems.). The defensiveness (DEF) scale identifies individuals who are unwilling to acknowledge minor, socially acceptable limitations or attempt to deny shortcomings and common flaws (i.e., True or False: Most people would lie to get what they want.). The supplemental addictions measure (SAM) scale consists of items that discriminate between SUD criterion groups and is used in the SASSI-4 decision rules (i.e., True or False: Sometimes I wish I could control myself better). These seven scales are utilized in a series of decision rules to produce a dichotomous screening classification. The SASSI-4 also contains two supplementary clinical scales. The aforementioned COR scale affords clinicians an opportunity to help divert their clients' negative behaviors (i.e., True or False: I break more laws than many people.). The Family vs. Controls (FAM) scale identifies individuals with characteristics common among family members of people with SUD (i.e., True or False: I have been tempted to leave home.). These two scales are not used to screen for SUD, but provide information that can be useful in evaluation and treatment planning. Additionally, the random answering pattern (RAP) scale is used to identify profile invalidity that might be due to deliberate noncompliance, insufficient reading comprehension, inattention, or other processes (i.e.,
True or False: Nearly everyone enjoys being picked on and made fun of.).

Below we present an example of a randomly selected case report called into our clinical consultation phone line by a professional using the SASSI-4 in a criminal justice counseling setting and used here with permission and client anonymity. Please note that the following case study is emblematic of the thousands of reports generated by SASSI scoring results. The SASSI-4 is a screening tool validated to identify high or low probability of an individual having an SUD. Scales scores on the SASSI can provide clinically useful information when above the $85^{\text {th }}$ percentile or below the $15^{\text {th }}$ percentile (this is the same as T-Scores above 60 and below 40) on the profile sheet (Figure 1). Recognizing these profile patterns may be of value in directing the ongoing course of assessment and treatment planning. Inferences drawn from SASSI scale score interpretation are hypotheses to explore based on years of feedback from professionals using the instrument.

\section{BRYON'S CASE STUDY}

For this case study, we reviewed the SASSI-4 screening results of a 24-year-old male whom we will call "Bryon". Bryon was in his $4^{\text {th }}$ week of detention at a local mid-western jail. He was arrested after turning himself in for a prior domestic violence offense committed while under the influence of alcohol and for which he had fled the state. Bryon had one prior arrest (for receiving stolen property, which he subsequently traded for drugs). The intake counselor conducting Bryon's assessment had been meeting with him at the jail for several weeks. The court was particularly interested in determining the level of risk that Bryon would again flee the area.

When examining a SASSI profile scale score (Figure 1), it is important to begin by looking at the information gathered from the RAP score (random responding) decision rule result, and level of defensiveness (DEF). Notice that Bryon seemed to respond to the SASSI items in a meaningful manner $(\mathrm{RAP}=0)$ and that there is 
no test evidence of defensive responding $(\mathrm{DEF}=4)$. The results of the decision rules indicate that he meets the criteria for classifying him as having a high probability of a substance use disorder as well as a high probability of prescription drug abuse $(\mathrm{Rx}=5)$.

Bryon acknowledges extensive and severe alcohol and drug problems $(F V A=21$ and $F V O D=28)$. Although he told his intake counselor that he has been abstinent for a period of several weeks prior to incarceration, his previously reported substance use history during his prior arrest included substantial substance-related problems including loss of control, negative consequences, and social functioning. Bryon also expressed regrets that his previous substance use has resulted in similar outcomes, and similar outcomes among many of his friends, that is, fights, arguments and arrests. It is important to note that Bryon's behaviors belie these regrets, as he is either in denial about his substance use disorder or has found himself within the destructive patterns of behaviors leading to a revolving door of drug use, arrests and inevitably, incarceration. Additionally, in Bryon's case these behaviors occur on an almost repetitive yearly basis. These behavior patterns also appear to be the rule among members of this population, rather than the exception.

There is significant evidence that Bryon's life experiences include living in social environments where the abuse of alcohol and other drugs, and associated consequences is a relatively common and routine occurrence (SYM=9). Despite Bryon's awareness of behavioral problems related to his drinking and drug use, the normalization of such problems in the milieu in which he lives may make it difficult for him to fully accept the severity of his addiction.

Examining the items Bryon endorsed on the FVA, FVOD, SYM and Rx scales may provide useful insight into his motivations for using, and help him see the consequences that have resulted from his use. In addition, Bryon's responses are remarkably similar to individuals with an SUD who often lack awareness and insight regarding the impact of alcohol and drug use on their psychological and emotional functioning (SAT=9). He may very well-be unaware of related symptoms such as emotional avoidance, fear of intimacy, and maintaining personal power and control. Despite these limitations, Bryon does seem to acknowledge some awareness of possessing behavioral characteristics and traits commonly associated with individuals who have substance use disorders (OAT=7). These may include such things as low frustration tolerance, impulsivity, self-centeredness, and irritability.

Bryon is at high-risk for continuing to incur legal problems given his high score on the Correctional Scale $(\mathrm{COR}=13)$. When making case disposition decisions, it is therefore important to take into consideration evidence that substance misuse increases the risk of impulse control problems and poor judgment. These issues need to be addressed in order to keep him out of future trouble with the law.

\section{Treatment Recommendations}

This case presents us with a good example of the value of early identification of substance use disorder, and potential problems in criminal justice settings. Bryon's SASSI results clearly demonstrate a well-established pattern of substance misuse that will require relatively intensive intervention. Therefore, he may be a solid candidate for diversion into an alcohol and drug treatment program as a way of reducing the risk of future offenses.

Treatment planning should include interventions designed to build upon Bryon's willingness to be open about his alcohol and drug problems. Efforts to increase his self-awareness and insight regarding the pervasive nature of substance use in his life would be valuable. Therapies including Motivational Interviewing and Cognitive Behavioral therapy are effective tools to increase his self-awareness and insight regarding the pervasive nature of substance use. ${ }^{16,17}$ These cognitive approaches may be beneficial in helping Bryon to reframe his view of the social environment in which he lives. Specific intervention for prescription drug abuse also needs to be addressed and Bryon should be evaluated as a candidate for a medically assisted treatment (MAT) program. Community self-help groups and therapeutic group modalities may also be particularly helpful in providing an environment that encourages abstinence and establishing new social support networks upon release.

Bryon's recommended level of care should include adequate supervisory support and structure to ensure successful completion of treatment and transition into after care. Anger management and impulse control issues should be addressed to further reduce the risk of continued domestic violence. Random toxicological screens, cognitively based behavior management strategies, and possible use of transitional living arrangements may also be of benefit.

\section{DISCUSSION}

According to the Center for Disease Control/US Department of Health and Human Services (HHS) (2014), abuse of prescription medications has become an epidemic. Among the most frequently abused prescription medications are opioid pain medications and sedatives prescribed for anxiety and sleep disorders. ${ }^{18}$ Inclusion of the prescription drug abuse scale $(\mathrm{Rx})$ on the SASSI- 4 to specifically identify individuals likely to be abusing prescription drugs was aimed at extending the clinical utility of the instrument by providing practitioners a measure of prescription medication abuse, in addition to the overall screening outcome for likely substance use disorder. ${ }^{2,14}$ In the case study sample provided here, we did not examine specific substances that Bryon may have used. However, when used as part of an overall assessment package, the SASSI-4's Rx scale can help identify individuals who may be attempting to self-medicate a physical pain problem or non-substance related psychological disorder. (See for example Table 1, which describes correspondence between SASSI-4 screening outcomes and DSM5 SUD diagnoses among clients with co-occurring or non-SUD related diagnoses).

A more comprehensive evaluation should be considered when an individual acknowledges prescription medication abuse. As the SASSI-4 was concorded with DSM-5 diagnostic criteria 
when constructed, it is particularly sensitive to detecting the presence of a clinically diagnosed substance use disorder. The sensitivity of SASSI-4 screening outcomes (i.e., the percentage of respondents diagnosed as having a substance use disorder who screened test positive on the SASSI-4) was $94 \%$ in the development sample and $93 \%$ in the validation sample, for an overall sensitivity of $93 \%{ }^{13}$

Substance abuse treatment for incarcerated offenders can reduce relapse and further criminal activities. ${ }^{19}$ The SASSI has been shown to demonstrate the characteristics that make it an ideal tool for this population-it is valid, reliable, inexpensive and easy to administer. ${ }^{20}$ It can also be scored with a narrative report electronically; allowing for no delay in obtaining results as staff time is not needed to score and interpret.

In addition to its use in criminal justice settings, the SASSI-4 can be used by anyone who needs to screen for alcohol and drug related disorders in a variety of settings (e.g., school counseling, military/veterans, behavioral health). The instrument is licensed for use by substance abuse counselors, educators, medical practitioners, criminal justice professionals, drug court personnel, employee assistance counselors, and therapists throughout North America, the United Kingdom, Greece, and Australia. ${ }^{1}$ The SASSI has been translated for research purposes into American Sign Language (ASL), Brazilian Portuguese, Bulgarian, Finnish, French, Greek, Japanese, Romanian, Russian, Slovene, and Spanish. Currently, the ASL, Spanish and Greek versions have been validated and are available for licensing. ${ }^{21-23}$

\section{LIMITATIONS}

It is important to realize that the SASSI is designed to identify people who are likely to have a substance use disorder regardless of whether or not the disorder is active or in remission. Therefore, recovering individuals may continue to show a "bigh probability of having a substance use disorder" even if they are in recovery.

\section{ACKNOWLEDGEMENT}

We wish to extend our gratitude to the many clinicians that reach out to us with questions and who share their experience with us regarding their use of the SASSI screening tool.

\section{CONFLICTS OF INTEREST}

The authors declare that they have no conflicts of interest.

\section{REFERENCES}

1. The National Center on Addiction and Substance Abuse. Bebind Bars II: Substance Abuse and America's Prison Population. New York, USA: Columbia University Press; 2010.

2. Lazowski LE, Geary BB. Validation of the adult substance abuse subtle screening inventory-4 (SASSI-4). European Journal of
Psychological Assessment.2019; 35(1): 86-97. doi: 10.1027/1015-5759/ a000359

3. Therapeutic Communities of America. Therapeutic Communities in Correctional Settings: The Standards Development Project: Phase II Final Report; 2002. Available from: Office of National Drug Control Policy | The White House Accessed January 25, 2021.

4. Tiburcio NJ, Twiggs R, DunlapE. Hurricane changes: Examining enhanced motivation to change drug using behaviors among Katrina evacuees. Anuario de Investigación en Adicciónes. 2009; 10(1): 79-95.

5. De Leon G. Is the therapeutic community an evidence based treatment? What the evidence says. International Journal of Therapeutic Communities. 2010; 31(2): 104-128.

6. Belenko S, Houser K, Welsh W. Understanding the impact of drug treatment in correctional settings. In: Petersilia J, Reitz KR, eds. The Oxford Handbook of Sentencing and Corrections. New York, NY, USA: Oxford University Press; 2012: 463-491.

7. Wexler H. The promise of prison-based treatment for dually diagnosed inmates. J Subst Abuse Treat. 2003; 25(3): 223-231. doi: 10.1016/s0740-5472(03)00121-1

8. De Leon G. The Therapeutic Community Theory, Model and Method. NY, USA: Springer Publishing; 2000.

9. Strauss SM, Tiburcio NJ, Munoz-Plaza C, Gwadz M, Lunievicz J, Osborne A, et al. HIV care providers' implementation of routine alcohol reduction support for their patients. AIDS Patient Care STDS. 2009; 23(3): 211-218. doi: 10.1089/apc.2008.0008

10. Tiburcio NJ, Kressel D. An enhanced understanding of therapeutic communities worldwide. Rev Adiccion Cienc. 2011; 1(4): 1-18.

11. Laux JM, Piazza NJ, Salyers K, Rosman CP. The substance abuse subtle screening inventory- 3 and stages of change: A screening validity study. Journal of Addictions \& Offender Counseling. 2012; 33: 82-92. doi: 10.1002/j.2161-1874.2012.00006.x

12. Lazowski LE, Miller GA. The Adolescent SASSI-A2 Updated User's Guide. Springville, Utah: The SASSI Institute; 2013.

13. Lazowski LE. Estimates of the Reliability and Criterion Validity of the Adult SASSI-4. Springville, Utah: The SASSI Institute; 2016.

14. Lazowski LE, Kimmell KS, Baker SL. The Adult Substance Abuse Subtle Screening Inventory-4 (SASSI-4) User Guide \& Manual. Springville, Utah: The SASSI Institute; 2016.

15. Melnick G, DeLeon G, Hiller ML, Knight K. Therapeutic communities: Diversity in treatment elements. Subst Use Misuse. 2000; 35(12-14): 1819-1847. doi: 10.3109/10826080009148242 
16. Miller WR, Rollick S. Motivational interviewing, $3^{\text {rd }}$ ed. In: Helping People Change. New York, NY, USA: Guildford Press; 2012.

17. Beck AT, Wright FD, Newman CF, Liese BS. Therapy of Substance Abuse. New York, NY, USA: Guilford Press; 2001.

18. Centers for Disease Control and Prevention (CDC). CDC WONDER. 2018. Web site. https://wonder.cdc.gov. Accessed January 30, 2021.

19. Pearson FS, Lipton DS. A meta-analytic review of the effectiveness ofcorrections-based treatment for drug abuse. The Prison Journal. 1999; 79(4): 384-410. doi: 10.1177/0032885599079004003

20. Kubiak SP, Boyd CJ, Slayden J, Young A. The substance abuse treatment needs of prisoners: Implementation of an integrated statewide approach. Journal of Offender Rehabilitation. 2005; 41(2):
1-19. doi: 10.1300/J076v41n02_01

21. Guthmann D, Lazowski LE, Moore D, Heinemann AW, Embree J. Validation of the Substance Abuse Screener in American Sign Language (SAS-ASL). Rehabilitation Psychology. 2012; 57(2): 140-148.

22. Lazowski LE, Boye MW, Miller GA, Miller FG. The Development and Validation of the Spanish SASSI. Springville, IN: The SASSI Institute; 2002.

23. Kontoleon P, Armaos R, Beratis I, Janikian M. Research presentation: Translation, cultural adaptation and psychometric properties of the Greek version of the substance abuse subtle screening inventory (SASSI-3). Paper presented at: $17^{\text {th }}$ European Federation of Therapeutic Communities (EFTC) Conference; September, 2019; Thessaloniki, Greece. 